Article:

\title{
Sensing parasites: Proteomic and advanced bio-detection alternatives
}

Carlos Sánchez-Ovejero, Fernando Benito-López, Paula Díez, Adriano Casulli, Mar Siles-Lucas, Manuel Fuentes, Raúl Manzano-Román

Journal of Proteomics 136 : 145-156 (2016)

This work is made available online in accordance with publisher policies. To see the final version of this work please visit the publisher's website. Access to the published online version may require a subscription.

\section{Link to publisher's version:}

http://dx.doi.org/10.1016/j.jprot.2015.12.030

Copyright statement: (c) 2016 Elsevier Ltd. Full-text reproduced in accordance with the publisher's self-archiving policy.

This manuscript version is made available under the CC-BY-NC-ND 4.0 license http://creativecommons.org/licenses/by-nc-nd/4.0

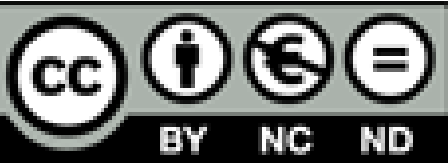




\section{Sensing parasites: proteomic and advanced bio-detection alternatives}

Carlos Sánchez-Ovejero ${ }^{1}$, Fernando Benito-Lopez ${ }^{2}$, Paula Díez ${ }^{3,4}$, Adriano Casulli ${ }^{5}$, Mar Siles-Lucas ${ }^{1}$, Manuel Fuentes ${ }^{3,4 *}$, Raúl Manzano-Román ${ }^{1 *}$

${ }^{1}$ Instituto de Recursos Naturales y Agrobiología de Salamanca (IRNASA-CSIC), 37008 Salamanca, Spain.

2 Analytical Chemistry Department, Universidad del País Vasco UPV/EHU, 01006 Vitoria-Gasteiz, Spain.

${ }^{3}$ Department of Medicine and General Cytometry Service-Nucleus, Cancer Research Centre (IBMCC/CSIC/USAL/IBSAL), 37007 Salamanca, Spain.

4 Proteomics Unit. Cancer Research Centre (IBMCC/CSIC/USAL/IBSAL), 37007 Salamanca, Spain.

${ }^{5}$ Department of Infectious, Parasitic and Immunomediated Diseases, Istituto Superiore di Sanità. Viale Regina Elena 299 - 00161 Rome, Italy

\section{*Corresponding authors:}

- Manuel Fuentes, PhD. Department of Medicine and General Cytometry ServiceNucleus, Cancer Research Centre (IBMCC/CSIC/USAL/IBSAL). Avda. Universidad de Coimbra S/N, 37007 Salamanca, Spain. Tel.: +34 923294811; Fax: +34 923294743.

E-Mail: mfuentes@usal.es.

- Raúl Manzano-Román, PhD. Instituto de Recursos Naturales y Agrobiología de Salamanca (IRNASA-CSIC). Cordel de Merinas 40-52. 37008 Salamanca, Spain. Tel.: +34 923219606; Fax: +34 923219609. E-Mail: raul.manzano@irnasa.csic.es. 


\begin{abstract}
Parasitic diseases have a great impact in human and animal health. The gold standard for the diagnosis of the majority of parasitic infections is still conventional microscopy, which presents important limitations in terms of sensitivity and specificity and commonly requires highly trained technicians. More accurate molecular-based diagnostic tools are needed for the implementation of early detection, effective treatments and massive screenings with high-throughput capacities. In this respect, sensitive and affordable devices could greatly impact on sustainable control programmes which exist against parasitic diseases, especially in low income settings.

Proteomics and nanotechnology approaches are valuable tools for sensing pathogens and host alteration signatures within microfluidic detection platforms. These new devices might provide novel solutions to fight parasitic diseases. Newly described specific parasite derived products with immune-modulatory properties have been postulated as the best candidates for the early and accurate detection of parasitic infections as well as for the blockage of parasite development.

This review provides the most recent methodological and technological advances with great potential for bio-sensing parasites in their hosts, showing the newest opportunities offered by modern "-omics" and platforms for parasite detection and control.
\end{abstract}

Keywords: detection platforms; diagnosis; proteomics; parasitic diseases; sensors; microfluidics. 


\section{Introduction}

Parasitic diseases represent particular challenges for human and animal health mainly in developing countries. They are strongly associated with poverty causing a considerable health and economic impact especially when considering co-introduced and co-invading parasites [1, 2]. Moreover, parasitic infections can be found worldwide and can be potentially introduced from endemic to non-endemic areas mainly due to human and animal population movements and climate change, resulting in their emergence and re-emergence $[3,4]$. Neglected parasitic infections are very prevalent especially among children and immunocompromised hosts -even in developed countries-, causing high morbidity and mortality rates $[5,6]$. The lack of appropriate diagnostic tools for many of these neglected diseases, combined with their lack of appropriate sensitivity and/or specificity, makes the investigation on new type of detection devices a must.

Zoonotic parasites are also the cause of substantive economic losses in livestock populations [2]. In this sense, the interest in understanding disease transmission among wild and domestic animals, and between them and human population has grown, resulting in the emergence of the "one health approach", which aims to model the transmission of parasitic diseases [7,8]. Detection and transmission control constitute significant components to the overall management of many pathogen infections (including parasites). Moreover, the rapid diagnosis of many complex parasitic diseases with on time treatments and tailored control measurements is essential to avoid sequelae, comorbidity and economic losses.

Drugs treatment remains as the principal approach for the control of parasites in animals; however parasites have shown molecular resistance mechanisms hampering this strategy. Successful and sustainable control strategies depend on the development of new tools for targeting both parasites/hosts and vectors [9]. To this end, applying new knowledge and techniques in combination with updated mass drug administration programmes is essential.

The Diagnosis of the most health impacting parasites is often cumbersome, where current diagnostic tests for important zoonotic parasitic diseases can provide incorrect results and so lead to unforeseen consequences [10]. Therefore, there is a much-need for rapid, simple, sensitive and affordable diagnostic tests to improve disease control and patient management, mainly in poor-resource settings where 
diseases like malaria or human sleeping sickness are endemic. In these scenarios, many people do not have access to laboratory facilities and many barriers technologies, costs and expertise lead to the necessity of incorporate point of care (POC) tests which offer flexibility, reliability and robustness for both, case detection and large population screenings [11].

Outside medical or veterinarian laboratories, rapid on-site diagnosis is very important in order to prevent and manage outbreaks and to apply appropriate prophylaxis, treatment and control programmes [12]. In this sense, biosensor-based tools developed for the diagnosis of pathogens is an emerging issue (131 PubMed papers from 2010 when searching "biosensor diagnosis pathogens" on December 2015) and ultimately a growing area of concern when referring to the diagnosis of parasitic infections (38 PubMed papers from 2010 when searching "biosensor diagnosis parasites" on November 2015).

The main goal of this emerging area of knowledge is to develop devices with multiplex capabilitites as suitable screening methods for the detection of several parasites and their corresponding vectors. Despite the recent advances in bio-sensor technology for infectious and parasitic diseases, they still remain as one of the major causes of mortality and morbidity throughout the world. This review presents current examples and perspectives for integrating modern sensing technologies for the detection of parasitic diseases.

\section{Predictive candidates to detect parasitic diseases}

Candidate biomarkers for the diagnosis of parasitic diseases must be identified in differentially expressed molecules between healthy subjects and infected patients. The first step towards an effective treatment of parasitic infections is an early detection and later differentiation of the disease progression and/or recurrences over time. Having into account the variations of the individual immune responses to the infection, the identification of candidate biomarkers is a more appropriate approach for reliable and specific parasite identifications than defining a single candidate. Thus, a combination of key hosts and parasite molecules is ideal to be included in target panels with the aim of achieving low overlapping between different diseases and therefore facilitate an integrated diagnosis.

Protein-protein interactions at the host-parasite interplay are highly relevant in the context of modifying protein expression levels and inducing protein expression. 
Identifying these alterations in host protein profiles during infection could facilitate the understanding of disease pathogenesis, host immune response, and identification of potential protein markers for the detection and prognosis of the disease. In this sense, parasitic infections may lead to highly relevant alterations on the level and expression of multiple serum proteins involved in essential physiological pathways (i.e. lipid-binding proteins) as well as in the change of very specific host molecules (i.e.- the host erythrocyte membrane proteins during malaria infection) $[13,14]$.

Investigating the metabolic consequences of parasitic infections in the host is now feasible based on modern technological advances. Experimental infections with single or multiple parasite species may allow the discovery of specific or common biomarkers, although they should be further validated in free living populations [15]. To this end, for example it has been shown by serum proteomics of Eimeria sp infected chickens that proteins usually not detected in the blood like those associated with mitochondrial metabolism are good candidates for time-course studies in coccidiosis. However, the host genetic background leading to different levels of susceptibility is a key factor in the alteration profile of proteins [16].

Regarding parasite derived molecules, the strategy to detect circulating antigens has the potential to discriminate active from past infections. Assessment of antigens during a given infection and specifically the excreted-secreted or surface-exposed parasite proteins, should be the best for an accurate immunodiagnostic procedure. The study of the surfome in parasites is revealing novel molecular targets for specific diagnosis. Many of these molecules are represented by glycoproteins located at the extracellular region attached to the plasma membrane, although antigenic variability at this level makes the selection of molecules cumbersome [17, 18]. This highlights the importance of comparative surfome analysis to increase the chance to find specific targets in parasites, leading to differential surface markers useful to avoid potential misdiagnosis like for example of Chagas' disease [17]. In addition, the potential detection of fine post-translational modifications creating neo-epitopes during specific parasitic disease pathogenesis could lead to monitor disease activity, like in many human diseases [19].

Epitope mapping studies aimed to identify unique diagnostic molecules from polymorphic immune-dominant antigens in parasites using computational methods is also a promising area [20]. For instance, the identification of many novel epitopes with diagnostic potential has been proved for the protozoan Trypanosoma cruzi [21]. 
Moreover, the detection of new diagnostic epitopes from circulating antigens is also a practical diagnostic strategy.

Some of the putative new protein biomarkers to detect parasites are likely to be present in biological fluids at extremely low concentrations and protected inside secreted microvesicles. Microvesicle-based secretion seems to be a general mechanism for protein secretion by protozoan parasites. It is well reported that the biomolecular cargo (i.e. proteins, lipids, nucleic acids) inside these microvesicles is involved in signalling for parasite infection and its survival therefore it could be also exploited in disease treatments $[22,23]$. Since extracellular vesicles are highly immunogenic, they can be considered as suitable candidates to detect parasitic diseases [23].

\section{Proteomic platforms for the identification of parasite biomarkers.}

Parasites have complex life-cycles and redundancy molecules can be found in many infectious processes, posing additional difficulties for their specific identification by classical biochemical approaches. Additionally, parasitic infections may alter the metabolic activities in their host being these alterations the basis of metabolic fingerprint approaches for understanding the metabolic consequences of the infections. Therefore, these could be considered as a source for novel diagnostic or prognostic biomarkers [15]. Nowadays, modern -omic technologies are offering high-throughput strategies for such a difficult system biology exploration, with the essential support of novel bioinformatic tools $[24,25]$.

The identification of biomarkers of parasitic infections by differential protein profiling of a specific host or parasitic molecules is a promising area; mainly based on induced changes by parasites at post-translational modifications, peptide degradations or protein variants [26]. Tissues (human and animal) and proximal bio-fluids could contain molecular information on the physiological and pathological state of the organism, since these tissues and bio-fluids are the route and destination of parasites and/or their secretions. The proteomic characterisation of proximal bio-fluids may provide useful and comprehensive information for diagnostic, prognostic and predictive biomarkers. The challenge is the detection of very low abundant protein circulating biomarkers -these kind of molecules provide a greater amount of downstream information content than nucleic acids- that may be essential for early diagnosis [27].

\subsection{The Potential of Mass Spectrometry}


Briefly, Mass Spectrometry (MS) is a robust, versatile and sensitive analytical technology allowing high-throughput detection with mass accuracy, precise quantisation and verification of protein variants, splice isoforms, metabolites and disease-specific post-translational modifications from tissues, body fluids or cell cultures [28, 29]. Highly sensitive technologies and high-throughput systems -like MS- are promising tools for novel biomarkers since MS allows characterisation of the fine tune changes in proteins, -including differences at population level- [30].

Commonly, MS-based proteomics approaches are a suitable resource to identify biomarkers for the detection of parasites as the main technique or coupled with other proteomic and conventional biochemical techniques. For instance, this is the basic for the identification of potential malarial markers in patient's sera and recently applied to identify specie-specific proteins in infected patients [31, 32].

De Bock and colleagues highlighted the potential of MS-based technologies (i.e. surface-enhanced laser desorption/ionisation time of flight mass spectrometry, SELDITOF-MS) as research tools to interrogate protein-based biomarkers in parasitic diseases. In general, SELDI-TOF determines differential specific protein profiles (in particular, low molecular weight molecules) in proximal bio-fluids. The above mentioned technology has also been applied in parasitic diseases by sensing unusually truncated host proteins in response to Trypanosoma cruzi infection with high sensitivity and specificity [33]. Moreover, matrix-assisted laser desorption ionisation time-of-flight (MALDI-TOF) is a valuable diagnostic technique already applied for detecting and differentiating Entamoeba Spp or Babesia canis canis infections, and becoming a miniaturised bioanalytical tool for detecting and discerning proteins from bio-complex samples [34-36]. MALDI mass spectrometry has applications in biomarker discovery, pathogen identification and has great potential for lipid-based biomarker sensing [37, 38]. For the identification of vectors like mosquitoes, MALDI-TOF allows accurate identifications which are important to elucidate their role as vectors. Importantly, the technique has also the potential for rapid in one-shot dual identifications (vectors and pathogens) [39, 40]. The utility of MS in routine analyses to point out markers of parasitic infections in bio-fluids and tissues was proved to be effective in many recent publications (Table 1), but still needs to be broadly used for research and clinical diagnosis. Many pre-analytical protocols during parasite sample preparation must focus on maximising the number of protein identifications on perform highly-reproducible assays. 
Other MS-based techniques, not predominately applied in diagnostic parasitology, but that hold great potential for the development of this area are:

(i) MS imaging is an analytical tool providing information on the spatial distribution and relative abundance of biomolecules in tissues [37]. Its power depends on an unbiased preliminary knowledge of molecular identities required, its ability to distinguish between diseases with similar histological characteristics, the different type of molecules detected, the quality of tissue preservation/conservation and the unique applications for clinical diagnostics [60]. It would probably be advantageous to correlate molecules and pathogenesis of impacting diseases like severe malaria, severe hepatosplenic schistosomiasis and cutaneous forms of leishmaniasis.

(ii) An emerging technology for pathogen detection is PCR-electrospray ionisation mass spectrometry, a versatile technique to characterise multiple strains and organisms having high potential to identify tick-borne pathogens $[61,62]$.

(iii) Multiple reaction monitoring mass spectrometric assays can be used in order to quantify multiple protein isoforms, specific proteins or modified peptides [63]. This technique requires enriched samples to accurately analyse modified biomolecules like lipopolysaccharides, glyco-sphingolipids and glycoproteins, which are highly relevant antigens of parasites [64].

(iv) Direct identification of compounds originated from pathogens physiology/metabolism within hosts can be done by metabolomic approaches [65]. Metabolomics profiles based on MS strategies detecting variations in differential metabolic signatures in cells, tissues or body fluids, may open a way for sensing parasites. When trying to detect and understand host or parasite derived metabolites at low concentration, capillary electrophoresis mass spectrometry with electrospray ionisation and gas-chromatography mass spectrometry offer valuable discriminatory power [66-68]. It could be also applied to time-course and accumulation of drug metabolites after treatment of parasitic diseases.

\subsection{Nanoproteomics}

Nanoproteomics is a new "-omic" emerging discipline coming from the advances and integration of nanotechnologies and proteomics, useful for rapid diagnostic screening at nanometer scale in the clinical practice. Nanotechnology has the potential to minimise most of the problems related to the proteomic technologies (i.e complexity, protein modifications and allows new methodological approaches such as 
multiplexing thus opening new biologically relevant insights) providing advantages at the detection level [69].

Multiplexing is an important feature that may facilitate the simultaneous study of different parameters within a unique platform. Protein and glycan microarrays, bead arrays or 3D printings are some of the methodologies included in this field within ondemand diagnostics platforms. The use of dynamic sensing arrays based on micron and/or nano-sized beads allows increasing the level of multiplexing with the potential to be adaptable in microfluidic devices for immunoassays [70]. Protein microarrays are miniaturised immunoassays in an array format which allows the study of thousands of proteins simultaneously, offering the opportunity to perform high-throughput screening for new biomarkers of infectious and parasitic diseases at global level [71, 72]. Moreover, peptide arrays could be powerful tools for deciphering epitope localisation: a combination of protein arrays followed by epitope scanning. Peptide chips could be a good strategy for the identification of potential immunodominant antigens and for epitopes description [73]. Biochips immuno-like polymer membranes for POC sensing of proteins in serum samples is also an interesting field [74]. In fact, novel singledomain antibodies (i.e. scFvs, nanobodies), may offer interesting advantages over monoclonal antibodies if applied to these methodologies [75, 76].

Glycan microarrays are also powerful tools for biomarker discovery. These microarrays have the potential to identify carbohydrate antigens and improve the serodiagnosis of different parasitic infections, although advanced methods for the synthesis, isolation, and characterisation of glycans are still required [77-79]. The diagnostic potential of glycans found in Leishmania, Schistosoma and Trichinella parasites points outs their relevance.

\subsection{Subcellular proteomics}

The analysis of the composition of particular purified cellular compartments is gaining importance in diagnostic research. Extracellular vesicles represent a promising source of circulating biomarker cargo encapsulated in a lipid coat. Among them, exosomes, 40-100 $\mathrm{nm}$ in size vesicles, which are important in inter-cellular communications, play critical roles in many biological functions. Exosome surface 
protein contents can be a rich source of biomarkers in blood samples and proximal fluids. These vesicles could have a high potential as optimal diagnostic targets based on the differential display of specific exosomal protein markers. Exosome-MS protein libraries prepared by either the shave -for surface protein exosomal markers- or complete exosome material, produce ideal peptide libraries for MS/MS analysis.

There is accumulating evidences of the release of inter-communicating extracellular vesicles in parasitic diseases, being an integral part of the parasite's infectious life cycle $[80,81]$. The potential that proteomics, especially mass spectrometry, show for sensing and deciphering the cargo of these parasite or host secreted biomarker enriched microvesicles is very high in the field of parasitic diseases diagnosis [82]. The detection of parasitic derived microvesicles would be highly valuable for example to diagnose and guide management of chronic and complex asymptomatic diseases, such as cystic echinococcosis or in vector transmitted infections like Leishmaniasis, in which exosomes are new identified virulence factors [81].

Molecules in the exosome cargo like the microRNAs have also great potential for the diagnosis of parasitic diseases [83]. Other type of analytes that could be studied in the exosome space, e.g. lipids, might represent good biomarkers to investigate in the near future. All these provide an important base to continue researching in parasite derived exosomes as diagnostic targets and demonstrating their utility as clinical biomarkers.

\section{Parasite testing: biosensor based platforms}

There is an important demand in parasitic disease diagnostics for portable and highly sensitive systems. Novel detection platforms have the potential to develop robust, multiplexed ultrasensitive protein detection devices with high efficiency, high data quality, and cost-effectiveness for the identification of pathogens and disease biomarkers in both well-equipped and/or limited clinical facilities [84].

Biosensors are also new molecular technologies that attempt to overcome many of the detection limits due to the low abundance of key biomarkers [85]. Some of these technologies have impressively improved sensitivity compared to conventional immunoassay approaches [86]. However, few biosensors have been developed and commercialised for the detection of infectious or no infectious diseases, but none of them for parasitic diseases. 
Biosensors can be used as point-of-care devices to detect host and parasite virulence and specific biomarkers, being good alternatives to current standard methods [87]. These biomarkers can be transferred to a biosensor format for multiplexed ultrasensitive sensing directly from proximal body fluids, enabling simultaneous detection of specific, to several evolutive forms, antibodies. This biomarker serves as revolutionary POC diagnostic technology to improve the prevention, control and treatment of parasitic diseases. The inclusion of species-specific markers for differential diagnosis and polymorphism detections would directly impact sensing and help to understand parasites. The integration of high-throughput -omic data, which is relevant to essential host-parasite interaction networks, within these biomarkers appears as the most accurate scenario to understand and guarantee infection status.

These devices have the potential to identify single molecules without the use of microscopes and moreover the same device could potentially be used for several different tests for biomarkers and bio-particles, providing an interesting alternative to standard tests like PCR [87]. This could be very advantageous in low-resource settings where people may not be well trained even in standard test and few technologies are well-established at a POC level, or where the conditions are not appropriated for analysis. These devices will be particularly useful to detect invasive infections or to prevent further disease spread, especially in populations at extreme poverty that still rely in conventional parasitological techniques.

Advanced developments for onsite diagnosis could come from single cell proteomic studies with a microfluidic antibody capture chip platform, through the use of capture antibodies which would be able to detect target markers in real clinical practice [88]. However, the impact of microfluidics on interesting markers like for example exosomes is still small. Therefore, interfacing biosensors with mass spectrometry is leading to the high-resolution identification of macromolecules and thus search for parasitic targets [89]. The interrogation of protein biomarkers in specific cell types and during defined periods in hosts constitutes a potential emerging area of research to provide key advances in the field of parasitology. This could be especially relevant for understanding (i) anti-parasite immune responses in different clinical forms of parasitic diseases (i.e Chagas disease) and their role driving the development of this disease and (ii) the systemic impact of parasitic infections.

The development of specific methodologies is still required to accomplish and integrate all the above technologies in a high quality and robust sensing device. The 
ultimate advances in bio-fabrication techniques allow creating biosensors with living cells in 3D to more closely model the in vivo cell environment, having these devices the potential to combine bio-sensing and therapeutic treatments [90]. The implementation of these tests on clinical applications might positively influence animal and human clinical management as well as significantly reduce costs.

\subsection{The potential of biosensors to detect and diagnose parasites}

The diagnosis of many parasitic diseases relies on showing parasites in tissue samples and on standard tests, nevertheless there are still gaps in the diagnosis of well know parasites or even in distinguishing between species and subspecies [ 91] Table 2). The lack of diagnostic tests influences decisively health care decisions. In general, parasitological techniques oriented to detection by microscopic examination have many disadvantages such as: they are mainly invasive, leads to misdiagnosis, require expert microscopists, they are time consuming and they possess lack of accuracy [112]. Moreover, many rapid diagnostic tests lack accuracy, validation, or both. At hospital level, but even more in the field, there is an increasing demand for better diagnostic tests to detect parasitic diseases at early stage.

The pathogenicity and life cycles of parasites are highly complex and governed by the parasite-host interactions. The trend is, instead of testing for a single biomarker, to identify panel of biomarkers that together may be better predictors of clinically relevant parasites towards efficient decision-making in individual POC settings. As commented previously, MS and proteomic techniques can assist as standard tools for the identification of infection induced up and down regulations that may serve as specific protein biomarkers. Moreover, host-derived metabolic and specific pathogenicity sensors would also play a role modulating parasitic disease progression to ensure survival and long-term persistence $[113,114]$.

In this sense, the infection and persistence by protozoan parasites is associated with changes in host tissue protein composition, highlighting that both parasite and host-derived molecules modulate disease progression [113, 115]. For instance, these kind of bidirectional protein signatures have been identified by proteomics in Plasmodium falciparum [116]. Also, in the management of the complex Echinococcosis, was recently suggested that a combination of markers would be highly desirable for the follow-up of threated patients to avoid recurrence [110]. Moreover, an 
integrative approach that looks for an effective diagnosis was also suggested for Schistosomiasis [117].

\subsection{The critical role of biosensors in important parasitic diseases.}

The broad technologies underlying biosensors have experienced many developments, with the goal to enable small, sensitive and easy-to-use devices. As mentioned in previous points, micro- and nanotechnologies can offer new technological tools and potential applications for developing bio-sensing devices for infection's biomarkers. Many of these biosensors have proven to be useful for the detection of pathogen signatures and circulating proteins in patients [118]. The access to timely and accurate diagnostic tests has a significant impact in the management of many parasitic diseases like malaria.

At present, many microfluidic platforms are under development in order to address the main disadvantages presented above. Microfluidics provide an ideal interface for the manipulation of cells (i.e. red blood cells) or even the microorganisms in a complete integrated system that can be fabricated in mass-production at low costs (table 3). These devices have the potential of contributing to the diagnosis, control and treatment of malaria. In the near future, by using a drop of blood obtained from a finger pick, these assays could be automated to reduce human interventions in sample analysis for easy and massive large population screenings.

Sissel Juul and colleagues developed an impressive device, based on droplet microfluidics, in 2012 [137]. The microfluidic device is able to specifically and sensitively detect malaria-causing Plasmodium parasites employing isothermal conversion of single DNA cleavage-ligation events catalysed specifically by the Plasmodium enzyme topoisomerase I and detectable at the single-molecule level. This device allows for sensitive, specific, and quantitative detection of all human-malariacaused by Plasmodium species in single drops from whole blood with a detection limit of less than one parasite $/ \mu \mathrm{L}$.

Very recently Warkiani and colleagues [138] developed a highly integrated system that allows enrichment and purification of malaria parasites from whole blood using a label-free, shear-modulated inertial microfluidic device. From 2 to 10 parasites were separated per millilitre and quantified using qPCR. This technique is approximately 100 -fold more sensitive than conventional microscopy analysis of thick 
blood smears and ideal for further integration into an automatic system with downstream detection for POC diagnostic devices.

Red blood cells (RBCs) infected with malaria can be easily detected using microfluidic devices by looking at the morphological changes on the surface of the RBCs. Using controlled surface roughness and shear forces in a microfluidic channel malaria infected RBCs can be slowed and eventually immobilised on the roughened surface from whole blood. Although not well optimised for being used as POC device, it is ambitioned to be an alternative biomarker for malaria diagnosis [124]. Following the same concept of looking at RBCs, Quan Guo and coworkers [128] developed a microfluidic technique for measuring the deformability of single RBCs based on their ability to deform through micrometre-scale constrictions. Although slow and tedious to extract information from the device is able to distinguish among uninfected RBCs and RBCs with various stages of $P$. falciparum infection.

Other ways of parasite detection are the fabrication of special flow-through separator structures inside the microfluidic channel for trapping parasites [139] or the apertures designed by Chunxiao $\mathrm{Hu}$ and collaborators [140] that form a trap were the parasite are trapped around a mid-point of its body. This type of traps have been used for differentiate plant parasitic nematodes by their stylet activity trough integrated electrodes that record electrical signals.

An interesting review reported some relevant biosensors developed in POC system for an important vector borne infection as dengue, highlighting their enormous potential in this field [141]. In general, technologies based on biosensors have been applied in diagnostic investigations of a wide range of parasites as can be seen in Table 4. In this way, advanced research through the integration of different techniques for multiplexing and high-throughput analysis on a chip might lead to the development of multi-parasite detection devices highly advantageous for tropical parasitic diseases [161, 162]. Moreover, microfluidic devices open new avenues to investigate full parasite behaviour [163, 164] and parasite drug response [165] in order to design new strategies to fight them. These technologies are also applicable in toxicology and drug discovery programmes for human metabolic studies and degenerative diseases.

In particular rapid developments are occurring in the field of paper based analytical devices ( $\mu$ PADs). $\mu$ PADs are a new type of analytical platforms for ASSURED diagnostic tests (Affordable, Sensitive, Specific, User friendly, Rapid and robust, Equipment free, Deliverable to end users, World Health Organisation). These 
devices should be simple to use, portable, inexpensive able to detect multiple analytes, and usable in use small volumes of sample. Therefore the perfect tools for parasite detection in developing countries are coming. For instance, Horning and co-workers [166] developed a paper microfluidic cartridge for the automated staining of malaria parasites with acridine orange prior to microscopy. The cartridge enables simultaneous, sub-minute generation of both thin and thick smears of acridine orange stained parasites, and has the potential to be used in limited-resources settings (Figure 1).

In the tropics and in the resource-limited settings, water-borne parasites are among the most important parasitic diseases and many obstacles prevent their detection [167]. There is a need for rapid and simple screening of water sources to protect human health from water-related diseases. Currently, information about compact imaging systems incorporating a chip-scale microscope brings light to the diagnosis of major enteric parasites to save many lives [168]. Also, devices can track infectivity as early as $12 \mathrm{~h}$ post-infection, faster than other state of the art techniques [169]. Therefore, efforts are needed to facilitate market entry of these new technologies and facilitate mechanisms for their implementation. It is believed that PADs represent a realistic alternative for low cost, mass production and marketable devices. Moreover, the transition of paper based microfluidic devices from the laboratory into the market need to be accomplished by providing the effective fluid flow control on paper and developing paper compatible easy and cheap sensing mechanisms.

Other important parasites are those food-transmitted, which are generally underdetected. These food-borne parasites have complex life cycles, which made difficult their control. In addition, few food-borne parasitic pathogens are effectively monitored in food [170]. Actually, there is a tremendous need to track back food-borne infections using new technologies such as biosensors due to their high specificity and potential to decrease the detection times [171].

\section{Conclusions and Perspectives}

An efficient diagnosis is very important for the prevention and treatment of infectious and parasitic diseases. Bio-sensing devices based on a high-throughput format could have a favourable impact on disease screening and control implementation. New proteomics developments and their adaptation to POC may allow in a near future to produce low cost devices, increasing the sensitivity and shortening the time of detection compared to conventional tools. 
In this sense, there is an important need to start developing and commercialising devices focusing on POC diagnostics applications in human and veterinary parasitology. These devices would favour the overall health of people in developing countries by taking broad and on time prevention and control measures and by assessing the treatment efficacy and facilitating the understanding the distribution patterns of hosts and vectors of important zoonotic parasitic diseases. Moreover, key biosensors might allow the on-site molecular characterisation of multi-parasite species bringing important information on the complex host-parasite interplay.

The convergence of proteomics and nanotechnology more likely will provide specific immune-sensors and immune-assays for detecting biomarkers related to infections. In this regards, the development of portable POC diagnostic tools for detecting circulating exosomes as biomarkers, therapeutic targets and signalling molecules of parasitic origin is a feasible and important goal in parasitology research. The integration of data from detected parasitic molecules and changes detected in host immune and metabolic responses to the infection might provide detailed sensory information for precise molecular-level diagnostics and monitoring tools.

\section{Acknowledgements}

This research was funded by HERACLES project (http://www.heracles-fp7.eu/) under the Seventh Framework Programme of the European Commission. FBL acknowledges the support of the Ramón y Cajal programme (Ministerio de Economía y Competitividad) and to Marian M. De Pancorbo for letting him to use her laboratory facilities at UPV/EHU. We also gratefully acknowledge financial support from the Carlos III Health Institute of Spain (ISCIII, FIS PI14/01538 and FIS PI12/00624), Fondos FEDER (EU) and Junta Castilla-León BIO/SA07/15. The Proteomics Unit belongs to ProteoRed, PRB2-ISCIII, supported by grant PT13/0001. P.D. is supported by a JCYLEDU/346/2013 Ph.D. scholarship.

\section{References}

\section{References}

[1] Lymbery AJ, Morine M, Kanani HG, Beatty SJ, Morgan DL. Co-invaders: The effects of alien parasites on native hosts. International journal for parasitology Parasites and wildlife. 2014;3:171-7. 
[2] Torgerson PR. One world health: socioeconomic burden and parasitic disease control priorities. Veterinary parasitology. 2013;195:223-32.

[3] Lipkin WI. The changing face of pathogen discovery and surveillance. Nature reviews Microbiology. 2013;11:133-41.

[4] Carlier Y, Truyens C, Deloron P, Peyron F. Congenital parasitic infections: a review. Acta tropica. 2012;121:55-70.

[5] Yansouni CP, Merckx J, Libman MD, Ndao M. Recent advances in clinical parasitology diagnostics. Current infectious disease reports. 2014;16:434.

[6] Barry MA, Weatherhead JE, Hotez PJ, Woc-Colburn L. Childhood parasitic infections endemic to the United States. Pediatric clinics of North America. 2013;60:471-85.

[7] Godfrey SS. Networks and the ecology of parasite transmission: A framework for wildlife parasitology. International journal for parasitology Parasites and wildlife. 2013;2:235-45.

[8] Patterson JE, Ruckstuhl KE. Parasite infection and host group size: a metaanalytical review. Parasitology. 2013;140:803-13.

[9] Lustigman S, Geldhof P, Grant WN, Osei-Atweneboana MY, Sripa B, Basanez MG. A research agenda for helminth diseases of humans: basic research and enabling technologies to support control and elimination of helminthiases. PLoS neglected tropical diseases. 2012;6:e1445.

[10] Schwarz NG, Loderstaedt U, Hahn A, Hinz R, Zautner AE, Eibach D, et al. Microbiological laboratory diagnostics of neglected zoonotic diseases (NZDs). Acta tropica. 2015; doi: 10.1016/j.actatropica.2015.09.003.

[11] Peeling R, Mabey D. Point-of-care tests for diagnosing infections in the developing world. Clinical Microbiology and Infection. 2010;16:1062-9.

[12] Mohd Hanafiah K, Garcia M, Anderson D. Point-of-care testing and the control of infectious diseases. Biomarkers in medicine. 2013;7:333-47.

[13] Khoontawad J, Laothong U, Roytrakul S, Pinlaor P, Mulvenna J, Wongkham C, et al. Proteomic identification of plasma protein tyrosine phosphatase alpha and fibronectin associated with liver fluke, Opisthorchis viverrini, infection. PloS one. 2012; 7:e45460.

[14] Gonzalez-Diaz H, Munteanu CR, Postelnicu L, Prado-Prado F, Gestal M, Pazos A. LIBP-Pred: web server for lipid binding proteins using structural network parameters; PDB mining of human cancer biomarkers and drug targets in parasites and bacteria. Molecular bioSystems. 2012;8:851-62.

[15] Balog CI, Meissner A, Goraler S, Bladergroen MR, Vennervald BJ, Mayboroda $\mathrm{OA}$, et al. Metabonomic investigation of human Schistosoma mansoni infection. Molecular bioSystems. 2011;7:1473-80.

[16] Gilbert ER, Cox CM, Williams PM, McElroy AP, Dalloul RA, Ray WK, et al. Eimeria species and genetic background influence the serum protein profile of broilers with coccidiosis. PloS one. 2011;6:e14636.

[17] Wagner G, Eiko Yamanaka L, Moura H, Denardin Luckemeyer D, Schlindwein $\mathrm{AD}$, Hermes Stoco $\mathrm{P}$, et al. The Trypanosoma rangeli trypomastigote 
surfaceome reveals novel proteins and targets for specific diagnosis. Journal of proteomics. 2013;82:52-63.

[18] Hull R, Dlamini Z. The role played by alternative splicing in antigenic variability in human endo-parasites. Parasites \& vectors. 2014;7:53.

[19] Karsdal MA, Henriksen K, Leeming DJ, Woodworth T, Vassiliadis E, Bay-Jensen AC. Novel combinations of Post-Translational Modification (PTM) neo-epitopes provide tissue-specific biochemical markers--are they the cause or the consequence of the disease? Clinical biochemistry. 2010;43:793-804.

[20] Lian Y, Ge M, Pan XM. EPMLR: sequence-based linear B-cell epitope prediction method using multiple linear regression. BMC bioinformatics. 2014;15:414.

[21] Carmona SJ, Sartor PA, Leguizamon MS, Campetella OE, Aguero F. Diagnostic peptide discovery: prioritization of pathogen diagnostic markers using multiple features. PloS one. 2012;7:e50748.

[22] Britton C, Winter AD, Marks ND, Gu H, McNeilly TN, Gillan V, et al. Application of small RNA technology for improved control of parasitic helminths. Veterinary parasitology. 2015;212:47-53.

[23] Mantel PY, Marti M. The role of extracellular vesicles in Plasmodium and other protozoan parasites. Cellular microbiology. 2014;16:344-54.

[24] Cantacessi C, Campbell BE, Jex AR, Young ND, Hall RS, Ranganathan S, et al. Bioinformatics meets parasitology. Parasite immunology. 2012;34:265-75.

[25] Cantacessi C, Hofmann A, Campbell BE, Gasser RB. Impact of next-generation technologies on exploring socioeconomically important parasites and developing new interventions. Methods in molecular biology (Clifton, NJ). 2015;1247:43774.

[26] De Bock M, de Seny D, Meuwis MA, Chapelle JP, Louis E, Malaise M, et al. Challenges for biomarker discovery in body fluids using SELDI-TOF-MS. Journal of biomedicine \& biotechnology. 2010;2010:906082.

[27] Qoronfleh M, Lindpaintner K. Protein biomarker immunoassays opportunities and challenges. Drug Discovery World. 2010;11:19-28.

[28] Baker ES, Liu T, Petyuk VA, Burnum-Johnson KE, Ibrahim YM, Anderson GA, et al. Mass spectrometry for translational proteomics: progress and clinical implications. Genome medicine. 2012;4:63.

[29] Di Girolamo F, Lante I, Muraca M, Putignani L. The Role of Mass Spectrometry in the "Omics" Era. Current organic chemistry. 2013;17:2891-905.

[30] Cunningham R, Ma D, Li L. Mass Spectrometry-based Proteomics and Peptidomics for Systems Biology and Biomarker Discovery. Frontiers in biology. 2012;7:313-35.

[31] Chen Y, Chan CK, Kerishnan JP, Lau YL, Wong YL, Gopinath SC. Identification of circulating biomarkers in sera of Plasmodium knowlesi-infected malaria patients--comparison against Plasmodium vivax infection. BMC infectious diseases. 2015;15:49.

[32] $\mathrm{Mu} \mathrm{AK}$, Bee PC, Lau YL, Chen Y. Identification of protein markers in patients infected with Plasmodium knowlesi, Plasmodium falciparum and Plasmodium vivax. International journal of molecular sciences. 2014;15:19952-61. 
[33] Ndao M, Spithill TW, Caffrey R, Li H, Podust VN, Perichon R, et al. Identification of novel diagnostic serum biomarkers for Chagas' disease in asymptomatic subjects by mass spectrometric profiling. J Clin Microbiol. 2010;48:1139-49.

[34] Kailasa SK, Wu HF. Proteomic profiling by nanomaterials-based matrix-assisted laser desorption/ionization mass spectrometry for high-resolution data and novel protein information directly from biological samples. Methods in molecular biology (Clifton, NJ). 2015;1295:479-96.

[35] Adaszek L, Banach T, Bartnicki M, Winiarczyk D, Lyp P, Winiarczyk S. Application the mass spectrometry MALDI-TOF technique for detection of Babesia canis canis infection in dogs. Parasitology research. 2014;113:4293-5.

[36] Calderaro A, Piergianni M, Buttrini M, Montecchini S, Piccolo G, Gorrini C, et al. MALDI-TOF mass spectrometry for the detection and differentiation of Entamoeba histolytica and Entamoeba dispar. PloS one. 2015;10:e0122448.

[37] Minerva L, Ceulemans A, Baggerman G, Arckens L. MALDI MS imaging as a tool for biomarker discovery: methodological challenges in a clinical setting. Proteomics Clinical applications. 2012;6:581-95.

[38] Arafah K, Longuespee R, Desmons A, Kerdraon O, Fournier I, Salzet M. Lipidomics for clinical diagnosis: Dye-Assisted Laser Desorption/Ionization (DALDI) method for lipids detection in MALDI mass spectrometry imaging. Omics : a journal of integrative biology. 2014;18:487-98.

[39] Uhlmann KR, Gibb S, Kalkhof S, Arroyo-Abad U, Schulz C, Hoffmann B, et al. Species determination of Culicoides biting midges via peptide profiling using matrix-assisted laser desorption ionization mass spectrometry. Parasites \& vectors. 2014;7:392.

[40] Fotso Fotso A, Mediannikov O, Diatta G, Almeras L, Flaudrops C, Parola P, et al. MALDI-TOF mass spectrometry detection of pathogens in vectors: the Borrelia crocidurae/Ornithodoros sonrai paradigm. PLoS neglected tropical diseases. 2014;8:e2984.

[41] Ndao M, Spithill TW, Caffrey R, Li H, Podust VN, Perichon R, et al. Identification of novel diagnostic serum biomarkers for chagas' disease in asymptomatic subjects by mass spectrometric profiling. Journal of Clinical Microbiology. 2010;48:1139-49.

[42] Wagner G, Eiko Yamanaka L, Moura H, Denardin Lückemeyer D, Schlindwein $\mathrm{AD}$, Hermes Stoco $\mathrm{P}$, et al. The Trypanosoma rangeli trypomastigote surfaceome reveals novel proteins and targets for specific diagnosis. Journal of proteomics. 2013;82:52-63.

[43] Tiberti N, Hainard A, Lejon V, Robin X, Ngoyi DM, Turck N, et al. Discovery and verification of osteopontin and Beta-2-microglobulin as promising markers for staging human African trypanosomiasis. Molecular \& cellular proteomics : MCP. 2010;9:2783-95.

[44] Robijn MLM, Planken J, Kornelis D, Hokke CH, Deelder AM. Mass spectrometric detection of urinary oligosaccharides as markers of Schistosoma 
mansoni infection. Transactions of the Royal Society of Tropical Medicine and Hygiene. 2008;102:79-83.

[45] Garcia-Perez I, Earll ME, Angulo S, Barbas C, Legido-Quigley C. Chemometric analysis of urine fingerprints acquired by liquid chromatography-mass spectrometry and capillary electrophoresis: application to the schistosomiasis mouse model. Electrophoresis. 2010;31:2349-55.

[46] Park YH, Shi YP, Liang B, Medriano CAD, Jeon YH, Torres E, et al. Highresolution metabolomics to discover potential parasite-specific biomarkers in a Plasmodium falciparum erythrocytic stage culture system. Malaria journal. 2015; 14:122.

[47] Tritten L, Keiser J, Godejohann M, Utzinger J, Vargas M, Beckonert O, et al. Metabolic profiling framework for discovery of candidate diagnostic markers of malaria. Scientific reports. 2013;3:2769.

[48] Zocevic A, Carmi-Leroy A, Sautereau J, d'Alayer J, Lenormand P, Rousselle J-C, et al. New markers in Anopheles gambiae salivary glands after Plasmodium berghei infection. Vector borne and zoonotic diseases (Larchmont, NY). 2013;13:119-27.

[49] Ahn C-S, Han X, Bae Y-A, Ma X, Kim J-T, Cai H, et al. Alteration of immunoproteome profile of Echinococcus granulosus hydatid fluid with progression of cystic echinococcosis. Parasites \& vectors. 2015;8:10.

[50] Wampfler PB, Tosevski V, Nanni P, Spycher C, Hehl AB. Proteomics of secretory and endocytic organelles in Giardia lamblia. PloS one. 2014;9:e94089.

[51] Ali IKM, Haque R, Siddique A, Kabir M, Sherman NE, Gray SA, et al. Proteomic analysis of the cyst stage of Entamoeba histolytica. PLoS neglected tropical diseases. 2012;6:e1643.

[52] Oakes RD, Kurian D, Bromley E, Ward C, Lal K, Blake DP, et al. The rhoptry proteome of Eimeria tenella sporozoites. International journal for parasitology. 2013;43:181-8.

[53] Saadatnia G, Mohamed Z, Ghaffarifar F, Osman E, Moghadam ZK, Noordin R. Toxoplasma gondii excretory secretory antigenic proteins of diagnostic potential. APMIS : acta pathologica, microbiologica, et immunologica Scandinavica. 2012;120:47-55.

[54] Wang L, Cui J, Hu DD, Liu RD, Wang ZQ. Identification of early diagnostic antigens from major excretory-secretory proteins of Trichinella spiralis muscle larvae using immunoproteomics. Parasites \& vectors. 2014;7:40.

[55] Deckers N, Dorny P, Kanobana K, Vercruysse J, Gonzalez AE, Ward B, et al. Use of ProteinChip technology for identifying biomarkers of parasitic diseases: the example of porcine cysticercosis (Taenia solium). Experimental parasitology. 2008;120:320-9.

[56] Magalhães-Junior JT, Mesquita PRR, Oliveira WFdS, Oliveira FS, Franke CR, Rodrigues FdM, et al. Identification of biomarkers in the hair of dogs: new diagnostic possibilities in the study and control of visceral leishmaniasis. Analytical and bioanalytical chemistry. 2014;406:6691-700. 
[57] Abeijon C, Kashino SS, Silva FO, Costa DL, Fujiwara RT, Costa CHN, et al. Identification and diagnostic utility of Leishmania infantum proteins found in urine samples from patients with visceral leishmaniasis. Clinical and vaccine immunology : CVI. 2012;19:935-43.

[58] Ramón-Luing La, Rendón-Gandarilla FJ, Cárdenas-Guerra RE, RodríguezCabrera Na, Ortega-López J, Avila-González L, et al. Immunoproteomics of the active degradome to identify biomarkers for Trichomonas vaginalis. Proteomics. 2010;10:435-44.

[59] Goldfinch GM, Smith WD, Imrie L, McLean K, Inglis NF, Pemberton AD. The proteome of gastric lymph in normal and nematode infected sheep. Proteomics. 2008;8:1909-18.

[60] Ye H, Gemperline E, Li L. A vision for better health: mass spectrometry imaging for clinical diagnostics. Clinica chimica acta; international journal of clinical chemistry. 2013;420:11-22.

[61] Wolk DM, Kaleta EJ, Wysocki VH. PCR-electrospray ionization mass spectrometry: the potential to change infectious disease diagnostics in clinical and public health laboratories. The Journal of molecular diagnostics: JMD. 2012;14:295-304.

[62] Eshoo MW, Crowder CD, Carolan HE, Rounds MA, Ecker DJ, Haag H, et al. Broad-range survey of tick-borne pathogens in Southern Germany reveals a high prevalence of Babesia microti and a diversity of other tick-borne pathogens.Vector Borne Zoonotic Dis. 2014;14:584-91.

[63] Parker CE, Borchers CH. Mass spectrometry based biomarker discovery, verification, and validation--quality assurance and control of protein biomarker assays. Molecular oncology. 2014;8:840-58.

[64] Timm T, Lenz C, Merkel D, Sadiffo C, Grabitzki J, Klein J, et al. Detection and site localization of phosphorylcholine-modified peptides by NanoLC-ESIMS/MS using precursor ion scanning and multiple reaction monitoring experiments. Journal of the American Society for Mass Spectrometry. 2015;26:460-71.

[65] Lv H, Hung CS, Chaturvedi KS, Hooton TM, Henderson JP. Development of an integrated metabolomic profiling approach for infectious diseases research. The Analyst. 2011;136:4752-63.

[66] Garcia-Perez I, Earll ME, Angulo S, Barbas C, Legido-Quigley C. Chemometric analysis of urine fingerprints acquired by liquid chromatography-mass spectrometry and capillary electrophoresis: application to the schistosomiasis mouse model. Electrophoresis. 2010;31:2349-55.

[67] Canuto GA, Castilho-Martins EA, Tavares M, Lopez-Gonzalvez A, Rivas L, Barbas C. CE-ESI-MS metabolic fingerprinting of Leishmania resistance to antimony treatment. Electrophoresis. 2012;33:1901-10.

[68] Ng Hublin JS, Ryan U, Trengove R, Maker G. Metabolomic profiling of faecal extracts from Cryptosporidium parvum infection in experimental mouse models. PloS one. 2013;8:e77803. 
[69] Kobeissy FH, Gulbakan B, Alawieh A, Karam P, Zhang Z, Guingab-Cagmat JD, et al. Post-genomics nanotechnology is gaining momentum: nanoproteomics and applications in life sciences. Omics : a journal of integrative biology. 2014;18:111-31.

[70] Manesse M, Phillips AF, LaFratta CN, Palacios MA, Hayman RB, Walt DR. Dynamic microbead arrays for biosensing applications. Lab on a chip. 2013;13:2153-60.

[71] Natesan M, Ulrich RG. Protein microarrays and biomarkers of infectious disease. International journal of molecular sciences. 2010;11:5165-83.

[72] Manzano-Roman R, Dasilva N, Diez P, Diaz-Martin V, Perez-Sanchez R, Orfao A, et al. Protein arrays as tool for studies at the host-pathogen interface. Journal of proteomics. 2013;94:387-400.

[73] Carmona SJ, Nielsen M, Schafer-Nielsen C, Mucci J, Altcheh J, Balouz V, et al. Towards high-throughput immunomics for infectious diseases: use of nextgeneration peptide microarrays for rapid discovery and mapping of antigenic determinants. Molecular \& cellular proteomics : MCP. 2015.

[74] Hong CC, Chen CP, Horng JC, Chen SY. Point-of-care protein sensing platform based on immuno-like membrane with molecularly-aligned nanocavities. Biosensors \& bioelectronics. 2013;50:425-30.

[75] Obishakin E, Stijlemans B, Santi-Rocca J, Vandenberghe I, Devreese B, Muldermans S, et al. Generation of a nanobody targeting the paraflagellar rod protein of trypanosomes. PloS one. 2014;9:e115893.

[76] Caljon G, Hussain S, Vermeiren L, Van Den Abbeele J. Description of a nanobody-based competitive immunoassay to detect tsetse fly exposure. PLoS neglected tropical diseases. 2015;9:e0003456.

[77] Muthana SM, Gildersleeve JC. Glycan microarrays: powerful tools for biomarker discovery. Cancer biomarkers : section A of Disease markers. 2014;14:29-41.

[78] Anish C, Martin CE, Wahlbrink A, Bogdan C, Ntais P, Antoniou M, et al. Immunogenicity and diagnostic potential of synthetic antigenic cell surface glycans of Leishmania. ACS chemical biology. 2013;8:2412-22.

[79] Aranzamendi C, Tefsen B, Jansen M, Chiumiento L, Bruschi F, Kortbeek T, et al. Glycan microarray profiling of parasite infection sera identifies the LDNF glycan as a potential antigen for serodiagnosis of trichinellosis. Experimental parasitology. 2011;129:221-6.

[80] Marcilla A, Martin-Jaular L, Trelis M, de Menezes-Neto A, Osuna A, Bernal D, et al. Extracellular vesicles in parasitic diseases. Journal of extracellular vesicles. 2014;3:25040.

[81] Atayde VD, Aslan H, Townsend S, Hassani K, Kamhawi S, Olivier M. Exosome Secretion by the Parasitic Protozoan Leishmania within the Sand Fly Midgut. Cell reports. 2015;13:957-67.

[82] Inal JM, Kosgodage U, Azam S, Stratton D, Antwi-Baffour S, Lange S. Blood/plasma secretome and microvesicles. Biochimica et biophysica acta. $2013 ; 1834: 2317-25$. 
[83] Manzano-Roman R, Siles-Lucas M. MicroRNAs in parasitic diseases: potential for diagnosis and targeting. Molecular and biochemical parasitology. 2012;186:81-6.

[84] Carrara S, Ghoreishizadeh S, Olivo J, Taurino I, Baj-Rossi C, Cavallini A, et al. Fully integrated biochip platforms for advanced healthcare. Sensors (Basel, Switzerland). 2012;12:11013-60.

[85] Battle KN, Uba FI, Soper SA. Microfluidics for the analysis of membrane proteins: how do we get there? Electrophoresis. 2014;35:2253-66.

[86] Wilson DH, Rissin DM, Kan CW, Fournier DR, Piech T, Campbell TG, et al. The Simoa HD-1 Analyzer: A Novel Fully Automated Digital Immunoassay Analyzer with Single-Molecule Sensitivity and Multiplexing. Journal of laboratory automation. 2015; Jun 15. pii: 2211068215589580.

[87] Sin ML, Mach KE, Wong PK, Liao JC. Advances and challenges in biosensorbased diagnosis of infectious diseases. Expert review of molecular diagnostics. 2014;14:225-44.

[88] Willison KR, Klug DR. Quantitative single cell and single molecule proteomics for clinical studies. Current opinion in biotechnology. 2013;24:745-51.

[89] Mu B, Zhang J, McNicholas TP, Reuel NF, Kruss S, Strano MS. Recent advances in molecular recognition based on nanoengineered platforms. Accounts of chemical research. 2014;47:979-88.

[90] Dias AD, Kingsley DM, Corr DT. Recent advances in bioprinting and applications for biosensing. Biosensors. 2014;4:111-36.

[91] Otranto D. Diagnostic challenges and the unwritten stories of dog and cat parasites. Veterinary parasitology. 2015;212:54-61.

[92] Muwonge H, Kikomeko S, Sembajjwe LF, Seguya A, Namugwanya C. How Reliable Are Hematological Parameters in Predicting Uncomplicated Malaria in an Endemic Region? ISRN tropical medicine. 2013;2013:1-9.

[93] Elbashir HM, Salih MM, Elhassan EM, Mohmmed AA, Elbashir MI, Adam I. Polymerase chain reaction and histology in diagnosis of placental malaria in an area of unstable malaria transmission in Central Sudan. Diagnostic pathology. 2011;6:128.

[94] Graffeo R, Masucci L, Bugli F, Damiano F, Pinnetti C, Federico G, et al. Multiple malaria infection in a pregnant woman from Nigeria: detection by multiplex PCR. The new microbiologica. 2008;31:565-7.

[95] Rogerson SJ, Mkundika P, Kanjala MK. Diagnosis of Plasmodium falciparum malaria at delivery: comparison of blood film preparation methods and of blood films with histology. J Clin Microbiol. 2003;41:1370-4.

[96] Diseases WHOobotSPfRaTiT. Malaria Rapid Diagnostic Test Performance. Results of WHO product testing of malaria RDTs: Round 3 (2010-2011). 2011.

[97] Mouatcho JC, Goldring JP. Malaria rapid diagnostic tests: challenges and prospects. Journal of medical microbiology. 2013;62:1491-505.

[98] Solca Mda S, Bastos LA, Guedes CE, Bordoni M, Borja LS, Larangeira DF, et al. Evaluating the accuracy of molecular diagnostic testing for canine visceral leishmaniasis using latent class analysis. PloS one. 2014;9:e103635. 
[99] Abass E, Kang C, Martinkovic F, Semiao-Santos SJ, Sundar S, Walden P, et al. Heterogeneity of Leishmania donovani parasites complicates diagnosis of visceral leishmaniasis: comparison of different serological tests in three endemic regions. PloS one. 2015;10:e0116408.

[100] Pereira VR, Reis Lde C, Souza Mde A, de Oliveira AP, de Brito ME, Lage PS, et al. Evaluation of anti-lived and anti-fixed Leishmania (Viannia) braziliensis promastigote $\mathrm{IgG}$ antibodies detected by flow cytometry for diagnosis and posttherapeutic cure assessment in localized cutaneous leishmaniasis. Diagnostic microbiology and infectious disease. 2012;74:292-8.

[101] Menezes-Souza D, Mendes TA, Nagem RA, Santos TT, Silva AL, Santoro MM, et al. Mapping B-cell epitopes for the peroxidoxin of Leishmania (Viannia) braziliensis and its potential for the clinical diagnosis of tegumentary and visceral leishmaniasis. PloS one. 2014;9:e99216.

[102] Bua J, Volta BJ, Perrone AE, Scollo K, Velazquez EB, Ruiz AM, et al. How to improve the early diagnosis of Trypanosoma cruzi infection: relationship between validated conventional diagnosis and quantitative DNA amplification in congenitally infected children. PLoS neglected tropical diseases. 2013;7:e2476.

[103] Afonso AM, Ebell MH, Tarleton RL. A systematic review of high quality diagnostic tests for Chagas disease. PLoS neglected tropical diseases. 2012;6:e1881.

[104] Machado-de-Assis GF, Silva AR, Do Bem VA, Bahia MT, Martins-Filho OA, Dias JC, et al. Posttherapeutic cure criteria in Chagas' disease: conventional serology followed by supplementary serological, parasitological, and molecular tests. Clin Vaccine Immunol. 2012;19:1283-91.

[105] Brasil PE, De Castro L, Hasslocher-Moreno AM, Sangenis LH, Braga JU. ELISA versus PCR for diagnosis of chronic Chagas disease: systematic review and meta-analysis. BMC infectious diseases. 2010;10:337.

[106] Khammari I, Saghrouni F, Lakhal S, Bouratbine A, Ben Said M, Boukadida J. A new IgG immunoblot kit for diagnosis of toxoplasmosis in pregnant women. The Korean journal of parasitology. 2014;52:493-9.

[107] Bergquist R, Johansen MV, Utzinger J. Diagnostic dilemmas in helminthology: what tools to use and when? Trends in parasitology. 2009;25:151-6.

[108] Cavalcanti MG, Silva LF, Peralta RH, Barreto MG, Peralta JM. Schistosomiasis in areas of low endemicity: a new era in diagnosis. Trends in parasitology. 2013;29:75-82.

[109] Hernandez-Gonzalez A, Santivanez S, Garcia HH, Rodriguez S, Munoz S, Ramos G, et al. Improved serodiagnosis of cystic echinococcosis using the new recombinant 2B2t antigen. PLoS neglected tropical diseases. 2012;6:e1714.

[110] Gottstein B, Wang J, Blagosklonov O, Grenouillet F, Millon L, Vuitton DA, et al. Echinococcus metacestode: in search of viability markers. Parasite (Paris, France). 2014;21:63.

[111] Conraths FJ, Deplazes P. Echinococcus multilocularis: Epidemiology, surveillance and state-of-the-art diagnostics from a veterinary public health perspective. Veterinary parasitology. 2015;213(3-4):149-61. 
[112] Wong SS, Fung KS, Chau S, Poon RW, Wong SC, Yuen KY. Molecular diagnosis in clinical parasitology: when and why? Experimental biology and medicine (Maywood, NJ). 2014;239:1443-60.

[113] Machado FS, Mukherjee S, Weiss LM, Tanowitz HB, Ashton AW. Bioactive lipids in Trypanosoma cruzi infection. Advances in parasitology. 2011;76:1-31.

[114] Mortimer L, Moreau F, Cornick S, Chadee K. Gal-lectin-dependent contact activates the inflammasome by invasive Entamoeba histolytica. Mucosal immunology. 2014;7:829-41.

[115] Nagajyothi F, Machado FS, Burleigh BA, Jelicks LA, Scherer PE, Mukherjee S, et al. Mechanisms of Trypanosoma cruzi persistence in Chagas disease. Cellular microbiology. 2012;14:634-43.

[116] Huang H, Mackeen MM, Cook M, Oriero E, Locke E, Thezenas ML, et al. Proteomic identification of host and parasite biomarkers in saliva from patients with uncomplicated Plasmodium falciparum malaria. Malaria journal. 2012;11:178.

[117] Silva-Moraes V, Ferreira JM, Coelho PM, Grenfell RF. Biomarkers for schistosomiasis: towards an integrative view of the search for an effective diagnosis. Acta tropica. 2014;132:75-9.

[118] Goulart LR, Vieira CU, Freschi AP, Capparelli FE, Fujimura PT, Almeida JF, et al. Biomarkers for serum diagnosis of infectious diseases and their potential application in novel sensor platforms. Critical reviews in immunology. 2010;30:201-22.

[119] Du E, Ha S, Diez-Silva M, Dao M, Suresh S, Chandrakasan AP. Electric impedance microflow cytometry for characterization of cell disease states. Lab on a chip. 2013;13:3903-9.

[120] Nam J, Huang H, Lim H, Lim C, Shin S. Magnetic separation of malaria-infected red blood cells in various developmental stages. Analytical chemistry. 2013;85:7316-23.

[121] Kataoka M, Abe K, Hashimoto Y, Yamamura S, Yatsushiro S. [Development of microchips for the analysis of biomarkers in blood]. Rinsho byori The Japanese journal of clinical pathology. 2012;60:1094-100.

[122] Taylor BJ, Howell A, Martin KA, Manage DP, Gordy W, Campbell SD, et al. A lab-on-chip for malaria diagnosis and surveillance. Malaria journal. 2014;13:179.

[123] Geislinger TM, Chan S, Moll K, Wixforth A, Wahlgren M, Franke T. Label-free microfluidic enrichment of ring-stage Plasmodium falciparum-infected red blood cells using non-inertial hydrodynamic lift. Malaria journal. 2014;13:375.

[124] Hsu YH, Lu P, Coleman JL, Tang WC. A microfluidic platform to isolate avian erythrocytes infected with Plasmodium gallinaceum malaria parasites based on surface morphological changes. Biomedical microdevices. 2011;13:995-1004.

[125] Jubery TZ, Dutta P. A new design for efficient dielectrophoretic separation of cells in a microdevice. Electrophoresis. 2013;34:643-50.

[126] Reboud J, Bourquin Y, Wilson R, Pall GS, Jiwaji M, Pitt AR, et al. Shaping acoustic fields as a toolset for microfluidic manipulations in diagnostic 
technologies. Proceedings of the National Academy of Sciences of the United States of America. 2012;109:15162-7.

[127] Herricks T, Seydel KB, Molyneux M, Taylor T, Rathod PK. Estimating physical splenic filtration of Plasmodium falciparum-infected red blood cells in malaria patients. Cellular microbiology. 2012;14:1880-91.

[128] Guo Q, Reiling SJ, Rohrbach P, Ma H. Microfluidic biomechanical assay for red blood cells parasitized by Plasmodium falciparum. Lab on a chip. 2012;12:114350.

[129] Lee SS, Yim Y, Ahn KH, Lee SJ. Extensional flow-based assessment of red blood cell deformability using hyperbolic converging microchannel. Biomedical microdevices. 2009;11:1021-7.

[130] Bow H, Pivkin IV, Diez-Silva M, Goldfless SJ, Dao M, Niles JC, et al. A microfabricated deformability-based flow cytometer with application to malaria. Lab on a chip. 2011;11:1065-73.

[131] Hou HW, Bhagat AA, Chong AG, Mao P, Tan KS, Han J, et al. Deformability based cell margination--a simple microfluidic design for malaria-infected erythrocyte separation. Lab on a chip. 2010;10:2605-13.

[132] Handayani S, Chiu DT, Tjitra E, Kuo JS, Lampah D, Kenangalem E, et al. High deformability of Plasmodium vivax-infected red blood cells under microfluidic conditions. The Journal of infectious diseases. 2009;199:445-50.

[133] Grover WH, Bryan AK, Diez-Silva M, Suresh S, Higgins JM, Manalis SR. Measuring single-cell density. Proceedings of the National Academy of Sciences of the United States of America. 2011;108:10992-6.

[134] Bishara W, Sikora U, Mudanyali O, Su TW, Yaglidere O, Luckhart S, et al. Holographic pixel super-resolution in portable lensless on-chip microscopy using a fiber-optic array. Lab on a chip. 2011;11:1276-9.

[135] Puskar L, Tuckermann R, Frosch T, Popp J, Ly V, McNaughton D, et al. Raman acoustic levitation spectroscopy of red blood cells and Plasmodium falciparum trophozoites. Lab on a chip. 2007;7:1125-31.

[136] Orban A, Butykai A, Molnar A, Prohle Z, Fulop G, Zelles T, et al. Evaluation of a novel magneto-optical method for the detection of malaria parasites. PloS one. 2014;9:e96981.

[137] Juul S, Nielsen CJ, Labouriau R, Roy A, Tesauro C, Jensen PW, et al. Droplet microfluidics platform for highly sensitive and quantitative detection of malariacausing Plasmodium parasites based on enzyme activity measurement. ACS nano. 2012;6:10676-83.

[138] Warkiani ME, Tay AK, Khoo BL, Xiaofeng X, Han J, Lim CT. Malaria detection using inertial microfluidics. Lab on a chip. 2015;15:1101-9.

[139] Laki AJN, G.Z. ; Ivan, K. ; Furjes, P. ; Jacso, O. ; Fok, E. ; Civera, P. Integrated microcapillary system for microfluidic parasite analysis Fac of Inf Technol \& Bionics. Budapest, Hungary IEEE; 2013. p. 118-21.

[140] Hu C, Kearn J, Urwin P, Lilley C, V OC, Holden-Dye L, et al. StyletChip: a microfluidic device for recording host invasion behaviour and feeding of plant parasitic nematodes. Lab on a chip. 2014;14:2447-55. 
[141] Teles FS. Biosensors and rapid diagnostic tests on the frontier between analytical and clinical chemistry for biomolecular diagnosis of dengue disease: a review. Analytica chimica acta. 2011;687:28-42.

[142] Cabral-Miranda G, de Jesus JR, Oliveira PR, Britto GS, Pontes-de-Carvalho LC, Dutra RF, et al. Detection of parasite antigens in Leishmania infantum-infected spleen tissue by monoclonal antibody-, piezoelectric-based immunosensors. The Journal of parasitology. 2014;100:73-8.

[143] Jeon W, Lee S, Manjunatha DH, Ban C. A colorimetric aptasensor for the diagnosis of malaria based on cationic polymers and gold nanoparticles. Analytical biochemistry. 2013;439:11-6.

[144] Tesauro C, Juul S, Arno B, Nielsen CJ, Fiorani P, Frohlich RF, et al. Specific detection of topoisomerase I from the malaria causing $\mathrm{P}$. falciparum parasite using isothermal rolling circle amplification. Conference proceedings : Annual International Conference of the IEEE Engineering in Medicine and Biology Society IEEE Engineering in Medicine and Biology Society Annual Conference. 2012;2012:2416-9.

[145] Potipitak T, Ngrenngarmlert W, Promptmas C, Chomean S, Ittarat W. Diagnosis and genotyping of Plasmodium falciparum by a DNA biosensor based on quartz crystal microbalance (QCM). Clinical chemistry and laboratory medicine : CCLM / FESCC. 2011;49:1367-73.

[146] Lee SA, Leitao R, Zheng G, Yang S, Rodriguez A, Yang C. Color capable subpixel resolving optofluidic microscope and its application to blood cell imaging for malaria diagnosis. PloS one. 2011;6:e26127.

[147] Angus SV, Kwon HJ, Yoon JY. Field-deployable and near-real-time optical microfluidic biosensors for single-oocyst-level detection of Cryptosporidium parvum from field water samples. Journal of environmental monitoring : JEM. 2012;14:3295-304.

[148] Park CK, Kang CD, Sim SJ. Non-labeled detection of waterborne pathogen Cryptosporidium parvum using a polydiacetylene-based fluorescence chip. Biotechnology journal. 2008;3:687-93.

[149] Taguchi T, Arakaki A, Takeyama H, Haraguchi S, Yoshino M, Kaneko M, et al. Detection of Cryptosporidium parvum oocysts using a microfluidic device equipped with the SUS micromesh and FITC-labeled antibody. Biotechnology and bioengineering. 2007;96:272-80.

[150] Wang S, Yin T, Zeng S, Che H, Yang F, Chen X, et al. A piezoelectric immunosensor using hybrid self-assembled monolayers for detection of Schistosoma japonicum. PloS one. 2012;7:e30779.

[151] Zeng S, Tian Z, Che H, Yang H, Chen X, Feng Q, et al. Novel printed electrode immunosensors for Schistosoma japonicum. Zhong nan da xue xue bao Yi xue ban = Journal of Central South University Medical sciences. 2012;37:541-8.

[152] Wen Z, Wang S, Wu Z, Shen G. A novel liquid-phase piezoelectric immunosensor for detecting Schistosoma japonicum circulating antigen. Parasitology international. 2011;60:301-6. 
[153] Linder E, Grote A, Varjo S, Linder N, Lebbad M, Lundin M, et al. On-chip imaging of Schistosoma haematobium eggs in urine for diagnosis by computer vision. PLoS neglected tropical diseases. 2013;7:e2547.

[154] Xu S, Mutharasan R. Rapid and sensitive detection of Giardia lamblia using a piezoelectric cantilever biosensor in finished and source waters. Environmental science \& technology. 2010;44:1736-41.

[155] Lee LM, Cui X, Yang C. The application of on-chip optofluidic microscopy for imaging Giardia lamblia trophozoites and cysts. Biomedical microdevices. 2009;11:951-8.

[156] Ribone ME, Belluzo MS, Pagani D, Marcipar IS, Lagier CM. Amperometric bioelectrode for specific human immunoglobulin $\mathrm{G}$ determination: optimization of the method to diagnose American trypanosomiasis. Analytical biochemistry. 2006;350:61-70.

[157] Pak BJ, Vasquez-Camargo F, Kalinichenko E, Chiodini PL, Nutman TB, Tanowitz HB, et al. Development of a rapid serological assay for the diagnosis of strongyloidiasis using a novel diffraction-based biosensor technology. PLoS neglected tropical diseases. 2014;8:e3002.

[158] Grewal YS, Shiddiky MJ, Spadafora LJ, Cangelosi GA, Trau M. Nano-yeast$\mathrm{scFv}$ probes on screen-printed gold electrodes for detection of Entamoeba histolytica antigens in a biological matrix. Biosensors \& bioelectronics. 2014;55:417-22.

[159] Nascimento E, Silva T, Oliva A. Identification, characterization and manipulation of Babesia-bovis-infected red blood cells using microfluidics technology. Parassitologia. 2007;49 Suppl 1:45-52.

[160] Cramp AP, Sohn JH, James PJ. Detection of cutaneous myiasis in sheep using an 'electronic nose'. Veterinary parasitology. 2009;166:293-8.

[161] Lam B, Das J, Holmes RD, Live L, Sage A, Sargent EH, et al. Solution-based circuits enable rapid and multiplexed pathogen detection. Nature communications. 2013;4:2001.

[162] Tan JJ, Capozzoli M, Sato M, Watthanaworawit W, Ling CL, Mauduit M, et al. An integrated lab-on-chip for rapid identification and simultaneous differentiation of tropical pathogens. PLoS neglected tropical diseases. 2014;8:e3043.

[163] Lockery SR, Hulme SE, Roberts WM, Robinson KJ, Laromaine A, Lindsay TH, et al. A microfluidic device for whole-animal drug screening using electrophysiological measures in the nematode C. elegans. Lab on a chip. 2012;12:2211-20.

[164] Lycke R, Parashar A, Pandey S. Microfluidics-enabled method to identify modes of Caenorhabditis elegans paralysis in four anthelmintics. Biomicrofluidics. 2013;7:64103.

[165] Carr JA, Parashar A, Gibson R, Robertson AP, Martin RJ, Pandey S. A microfluidic platform for high-sensitivity, real-time drug screening on C. elegans and parasitic nematodes. Lab on a chip. 2011;11:2385-96. 
[166] Horning MP, Delahunt CB, Singh SR, Garing SH, Nichols KP. A paper microfluidic cartridge for automated staining of malaria parasites with an optically transparent microscopy window. Lab on a chip. 2014;14:2040-6.

[167] Connelly JT, Baeumner AJ. Biosensors for the detection of waterborne pathogens. Analytical and bioanalytical chemistry. 2012;402:117-27.

[168] Lee SA, Erath J, Zheng G, Ou X, Willems P, Eichinger D, et al. Imaging and identification of waterborne parasites using a chip-scale microscope. PloS one. 2014;9:e89712.

[169] Dibao-Dina A, Follet J, Ibrahim M, Vlandas A, Senez V. Electrical impedance sensor for quantitative monitoring of infection processes on HCT-8 cells by the waterborne parasite Cryptosporidium. Biosensors \& bioelectronics. 2015;66:6976.

[170] Newell DG, Koopmans M, Verhoef L, Duizer E, Aidara-Kane A, Sprong H, et al. Food-borne diseases - the challenges of 20 years ago still persist while new ones continue to emerge. International journal of food microbiology. 2010;139 Suppl $1:$ S3-15.

[171] Dhama K, Rajagunalan S, Chakraborty S, Verma AK, Kumar A, Tiwari R, et al. Food-borne pathogens of animal origin-diagnosis, prevention, control and their zoonotic significance: a review. Pakistan journal of biological sciences: PJBS. 2013;16:1076-85.

\section{Figure legends:}

Figure 1: New type of analytical paper microfluidics for sensing parasites. A) A 3D representation of the cartridge. B) A top-down view of the cartridge. C) A cross-section of the cartridge, emphasizing the slanted nature of the coverslip during use, which permits imaging in both thick (many cells) and thin (single cell) regions. Reproduced with permission from [Matthew P. Horning et al 2014] (C) 2014, The Royal Society of Chemistry. 
